\title{
Cloud Based Platform Design for Court File Sharing
}

\author{
Meseret Girma Bekele Tekalign Tujo Gurmessa \\ Department of computer Science, College of computing, Madda Walabu University, \\ P.O. box 247, Bale Robe, Ethiopia
}

\begin{abstract}
Courts are very important organization over the whole world they have a vital roles for countries to make this organization secure reliable and flexible this organization must be related with information technology (IT).Information technology has many alternatives like we can make desktop application for the court or we can make web based application these all technologies can make the organization modernize but they have some drawback they need maintenance that can be complex for user, need very skilled person, and there will be other problems so to be over came over this problems information technology gives us another new technology that is cloud computing. In courts there are a lot of file all this files are shared by different employers in the institution.in these time the manual file sharing system is not more secure, not fast, user cannot get the file when they needed and there are a lot of complain that raised by user sometime file cannot available or there is a duplication of file so, for making this file sharing more secure, fast, on time and having a file at any time when they need the study use cloud computing technology. Open Shift Online 3.5 is used for doing the application.
\end{abstract}

Keywords: File sharing, Cloud Computing, Infrastructure as a service (Iaas), Open shift, Red Hat

DOI: $10.7176 / \mathrm{CEIS} / 10-3-01$

Publication date: April $30^{\text {th }} 2019$

\section{Introduction}

ICT can give the ability for the courts officer to posting, accessing and sharing of file through the world electronically. This thing can increase the productivity of courts file sharing, we can handle the file in good manner means court file are need confidentiality the file is all about privacy of people or the government so this file need more security so to do this technology is the good way because cloud computing has some security mechanism like authorization of the user only an authorized person can access or share file. Cloud systems can be used to enable data sharing capabilities and this can provide an abundant of benefits to the user. There is currently a push for IT organizations to increase their data sharing efforts. According to a survey by InformationWeek, nearly all organizations shared their data somehow with $74 \%$ sharing their data with customers and $64 \%$ sharing with suppliers. A fourth of the surveyed organizations consider data sharing a top priority. The benefits organizations can gain from data sharing are higher productivity. With multiple users from different organizations contributing to data in the Cloud, the time and cost will be much less compared to having to manually exchange data and hence creating a clutter of redundant and possibly out-of-date documents. (Danan Thilakanathan, 2014)

The importance of data sharing and the need to ensure privacy and security is discussed in a number of existing articles. A reliable and accurate file sharing is fundamental to the effectiveness of day-to-day court operations and fairness of judicial decisions. (W. S. W. M. S. a. A. Haider, 2012) The explosion of sophisticated information and communication technologies (ICTs) creates new opportunities as well as challenges for the whole service delivery systems, particularly to fulfill the ever increasing demand of citizens who are mostly having high level of information technology (IT) literacy and advanced in knowledge and awareness of their rights. To remain competitive, government record must progress in line with IT advancement, without compromising the existing strict government principles and regulations set through acts and policies (W. S. W. M. S. a. A. Haider, 2012). Cloud computing is one part of information communication technology system. Cloud computing is a model for delivering IT services. Instead of a direct connection to the server, the resources are retrieved from the Internet through web-based tools and applications.Therefore this research will try to make a cloud computing framework for court case management system to make the system efficient, effective and secure. Cloud computing technology is garnering success and wisdom-like stories of savings, ease of use, and increased flexibility in controlling how resources are used at any given time to deliver computing capability. (Stephen Kaisler, 2012) The cloud computing adoption framework defines the two intersecting dimensions that should be considered when developing a cloud computing strategy the delivery model and the type of service or services being delivered. When these two primary considerations are combined, a basic adoption framework for examining cloud implementation requirements and options emerges. Understanding these requirements can help organizations select the optimum combination of delivery model and service type for each workload they want to deploy in a cloud environment. Workloads are the kind of work that an organization needs to accomplish. Each workload has characteristics that make it more appropriate for public or for private cloud delivery, and more appropriate for a specific service type. (Stephen Kaisler, 2012)

So our study is to design a cloud based platform for file sharing of Ethiopian courts to create effective and 
good file sharing for the employer of the institution and this technology can help the worker to share file easily, to share knowledge, to share different experiences and also for having an information in a time all employer in any courts of the country can have an information about the same things.

\section{Methodology \\ Research design}

A research design is the systematic plans and procedures that a researcher develops to study a scientific problem. For most research study there are three type of research design this are Qualitative, Quantitative and Mixed research design. Research design are the plan or proposal to conduct research Involves the intersection of philosophy, strategies of inquiry, and specific methods to translate the design into research practice. It helps to explain why we choose qualitative, quantitative or mixed methods. It help to clarify how the world view shape the approach to research, as they are a basic set of beliefs that guide actions They are shaped by the discipline area, the academic supervisor and prior experience to research.. (rako, 21. may 2014)

Quantitative research design approach is an approach that Testing objective theories by examining the relationship among variables, Replicable, generalizable, Manipulation and control Results verified by sense data and statistics and the inquiry of this approaches experimentally that control and manage the study, Non experimental that include survey research, Longitudinal Cross sectional, Structured interview and other. The other one is Qualitative research design approach exploring for insights and understandings about individual perception of events by subjects Inductive data analysis from patterns and themes, from particular to general Interpretative Tendencies. On the other hand it is good for Narrative research (life story research) Phenomenology (Focus on human experiences about a phenomenon) Ethnography (cultural group in natural settings). Grounded theory studies (derives a general abstract theory of a process, action or interaction grounded in the views of participants) Case studies (explores a program, event, activity, process or individual) Historical (Identification, Location, Evaluation and Synthesis of data from the past to connect past happenings to the present and future). The last one is mixed method research design approach Combine both forms for data collection, it use both approaches in tandem to strengthen the study by data triangulation. And the strategic inquiry of this approach is Sequential (Elaborate or expands on the findings from one method with another method) Concurrent (merge quantitative/qualitative methods to provide a comprehensive analysis simultaneously) Transformative (The use of a theoretical lens as an overarching perspective). (rako, 21. may 2014)

So to select the design type there are three criteria for selection the first one is depend on research problem if the problem is about Identification of factors that influence an outcome utility of an invention, Understanding the best predictors of outcome, Evaluating the usefulness or successes of and intervention. Then a quantitative approach is best, If the problem is about understanding a concept or phenomenon explore a field uncertain about which are the most important variables to be examined therefore for such thing a qualitative approach is best. and if the question is need to be sublemented by the other the second criteria is Audience Acceptance from all involved Editors, Readers, Scientific ,community, ethical comities and research boards the last one is Personal experiences, Training experiences, Beliefs and Personality. (rako, 21. may 2014)

Therefore by considering the criteria in this study the researcher selects Qualitative research approach to design the platform because this approach is best for this study it include deep finding of knowledge and doing the research in qualitative way therefore this study need deep searching of data and it gives qualitative design for the user so it is best to use qualitative approach. qualitative research methods are usually associated with inductive approaches (based on empirical evidence). (Wyk, may 2013) Qualitative research usually requires Boolean measurements only. Suitability of a solution can be studied qualitatively.so depend on such reason the researcher is done this research by using qualitative research design approach for doing perfect study.

\section{Process Model}

Research process model is a model that used to describe the all activities of the research. Cloud computing system architecture presents the task to large scale computing centers that shared by all users on internet. User can share the resources of computer, hardware, software and other computing resources, and service resources like installation, configuration and maintenance for those resources. (1Kavita, April - June 2012) The cloud computing model has designed for the purpose of managing and coordinating the execution of supply chain by different activities. (1Kavita, April - June 2012) 


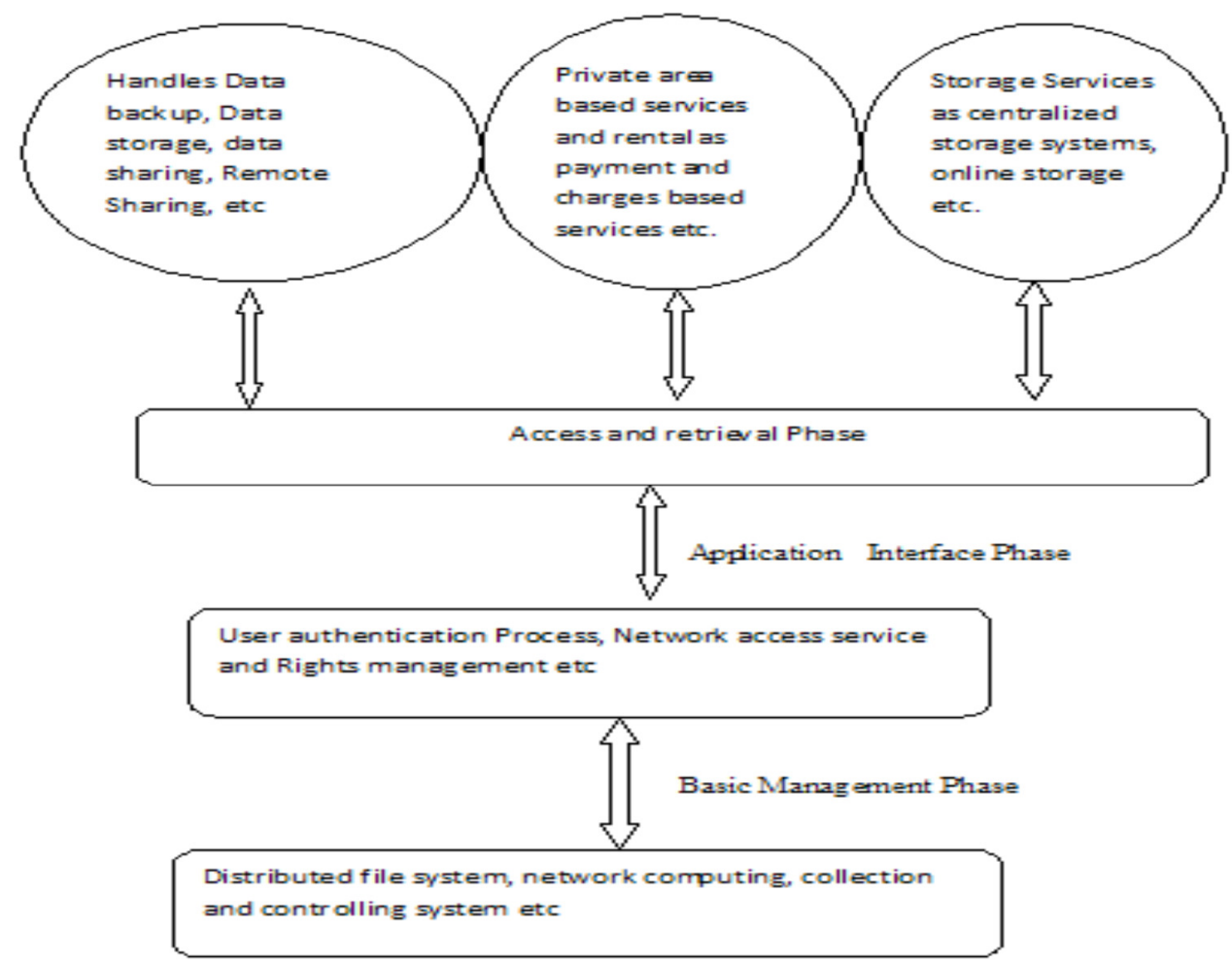

Figure: Cloud Computing System Architecture Model

\section{Data source}

In this research the researcher used two types of sources for conducting the data that can help to get a deep knowledge about the research; those are primary data gathering and secondary data gathering sources. for the primary data gathering we use interview and observation and for secondary data gathering we use analyzing of documents.

* Interviewing which is the primary data collection method that is asking a question directly the employers of the courts including judges, lawyer and other worker.in these case the researcher select two courts the first one is Akaki Primary Court (APC) and Kality Hgih Court (KHC).

* Document analysis which is secondary source and reviewing of different research papers that have related idea with this study from the Internet therefore Internet is also the source for gathering of data. In this case the researcher also analysis documents and reviews the papers which are found in library.

* The third one is observation it is a primary data collection method that performed by observing the activities of the courts, how files are stored, how this files are shared, what are the problems for storing file, what are the problem in file sharing and different activities that concerning about file and file sharing. Generally it is better for understanding the problem and for conducting data.

\section{Sampling Technique}

Sampling involves the selection of individuals, units, and/or settings from a defined study area. There are different sampling techniques in qualitative research to sample the research participants. This includes purposive sampling, snowball sampling, quota sampling, typical case sampling, convenience sampling and others. In this study, purposive sampling technique was used to collect the qualitative data. So data collection was started by identifying the employers using purposive sampling technique. Purposive also known as judgment or selective sampling technique is mostly used technique in qualitative research due to the qualities the informant possesses. Court employers from different court office institutions were chosen directly through personal contact. The court officer and other concerned bodies were selected based on appropriateness for the study; the knowledge they have and technology used, because this technique uses appropriateness principles in place of random sampling.

\section{Data Collection and Analysis}

For collection and analysis of data this study is focus on two courts this are Akaki Primary Court (APC) and Kality Higher Court. In these offices the researcher interviews the professionals in the area because this enable us to collect data correctly as well as it makes the data collection procedure easier. In this study as we describe before there are two data collection methods and in the first method we interview 20 court Employee to understand the 
idea of them about file sharing of the court, what is the current situation of the court, what are the problem of file sharing in the court, about the solution, if they have some idea about cloud computing and asking their that they have a welling if cloud based platform is implement for their organization.

The second one is observation in this method the researcher try to observe what is going in the organization, the employer adaption of technology, how they can store, share, search and update file and how can they make secure their data. To understand the ability, the confidentiality of the files and the whole performance of the court in file sharing the researcher try the best, because to know and understand all things about file sharing in the court by observation is very difficult.

To summarize, this study conduct different information and data by using interview and observation. To conduct data by using interview first we prepare the question that contain about how in the court files are shared from one office to other, what are the problem during file sharing, during storing file, does the file are secure, does they have some knowledge about cloud computing, can ICT give some benefits, if what are the benefit of ICT, does they used other related technology and other related questions are asked by the researcher directly.

This interview is mainly focus on the importance of cloud based file sharing for Ethiopian court file sharing system. how the employers are share their file, what are the difficulties and efforts of the employer during file share and bout the use of technology.

For the first time the researcher making interview for the employee that are working in Akaki Primary Court and as they explained even if some other researcher implemented different technology for their organization all systems are not in practice and the other system are used only to store data and file in data base and the employers can search on files from data base this systems are not that much important for file sharing they are using manual system for sharing and to have file, this thing is very difficult, it need more efforts of the worker, it take time, the sharing may not be secure so because of this thing the confidentiality of file will in risk ,the privacy of public will in question mark, things can not working in time, there will be the loss of data or duplication of data, for having some information the employer like police man or others should be appear and meet physically, people cannot appear on a time this thing will make the public or the employer uncomforted by the existing system. They list so many problems and they tell us it will be better if these cloud computing platform design be implement for giving some importance for the court file sharing.

For the other hand the researcher interview the workers of Kality Higher Court and they tell us all thing that listed before they have almost the same problems on file sharing. As we know This file sharing is the main and very important activities of the court it should have some support by ICT these can make the sharing very fast, secure and modernized therefore they give an idea it will be better this file sharing is performed by cloud based system.

All interviewer are telling us many time researcher can do many researches on this area but the system are not get practice so it is best to change the design in practice because as they told file sharing is a very important and it need carful sharing and it takes very long time so to overcame those and other problem practical of technology is best. To make change on any area technology has very important impacts so by using the technology we can do things better.

The other thing that include in the interview is about cloud computing and the researcher ask a question for worker about cloud if they have some knowledge about cloud but they have no any knowledge about it they did not know anything about cloud technology, before this interview they did not listen about it, but they tell us may this cloud computing increase the availability, security, confidentiality of court file sharing and decrease the time and money that take before so it is good to use cloud computing technology.

The main objective of this study was, to use the current technology for sharing and accessing file in Ethiopian court office to solve the problem of file sharing, confidentiality of file, security, knowledge sharing and networking and collaboration center. Cloud computing based platform architecture was proposed to solve the problem through sharing of all files to all courts employer at all level. Cloud computing has a solution for storing and processing large amount of documents, for sharing and accessing these resources with cost effective, flexible, scalable and multi-tenant way. This will help the court workers to develop ability, experience and knowledge, problem solving skill and technology adaption in their profession by accessing the shared resources using their existing ICT infrastructures ubiquitously.

\section{Result and Discussion \\ Implementation overview}

The CBPCFS system is designed to be simple/smart to look at and easy to access the available files and documents, the user can have user friendly r/ship with court file sharing providers and other employers who share their file and knowledge for others. The technologies that were used for development of the prototype are:

$>\mathrm{JS}, \mathrm{JQ}, \mathrm{HTML}$ and CSS for designing the web interface of the web application

$>$ PHP language for backend side of the prototype

$>$ Open Shift online platform for creating and testing the CBPCFS application 
$>$ Web and embedded cartridges to support languages and databases on the Open Shift online

$>$ RHC client to manage the code

$>$ Git repository to clone and deploy locally developed prototype on Open Shift online

The prototype is designed for both desktop and Laptop devices. Figure 25 shows the developed application in Open Shift online web console with the associated gears and cartridges. A screenshot or web interface of the homepage for desktop or laptop view are displayed on the next diagram.

OPENSH IF T ONLINE

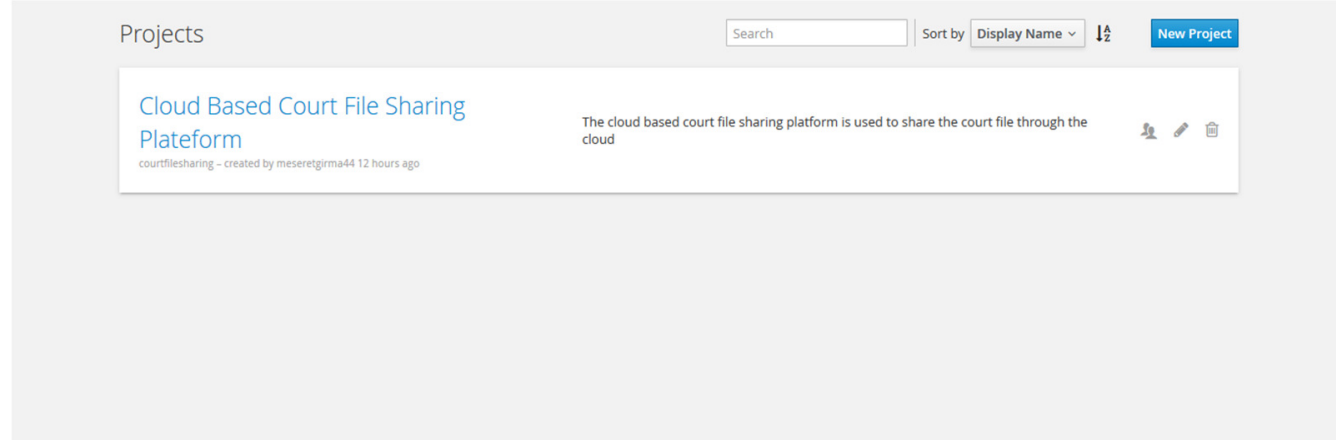

Figure:: The developed cloud based court file sharing application on the cloud

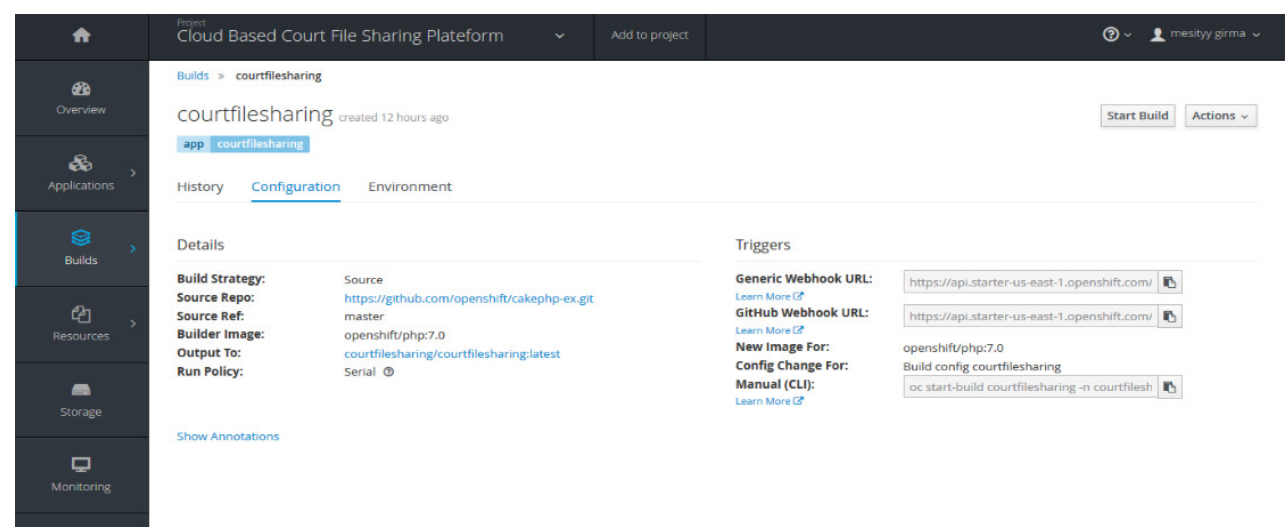

Figure:: Build description of court files haring

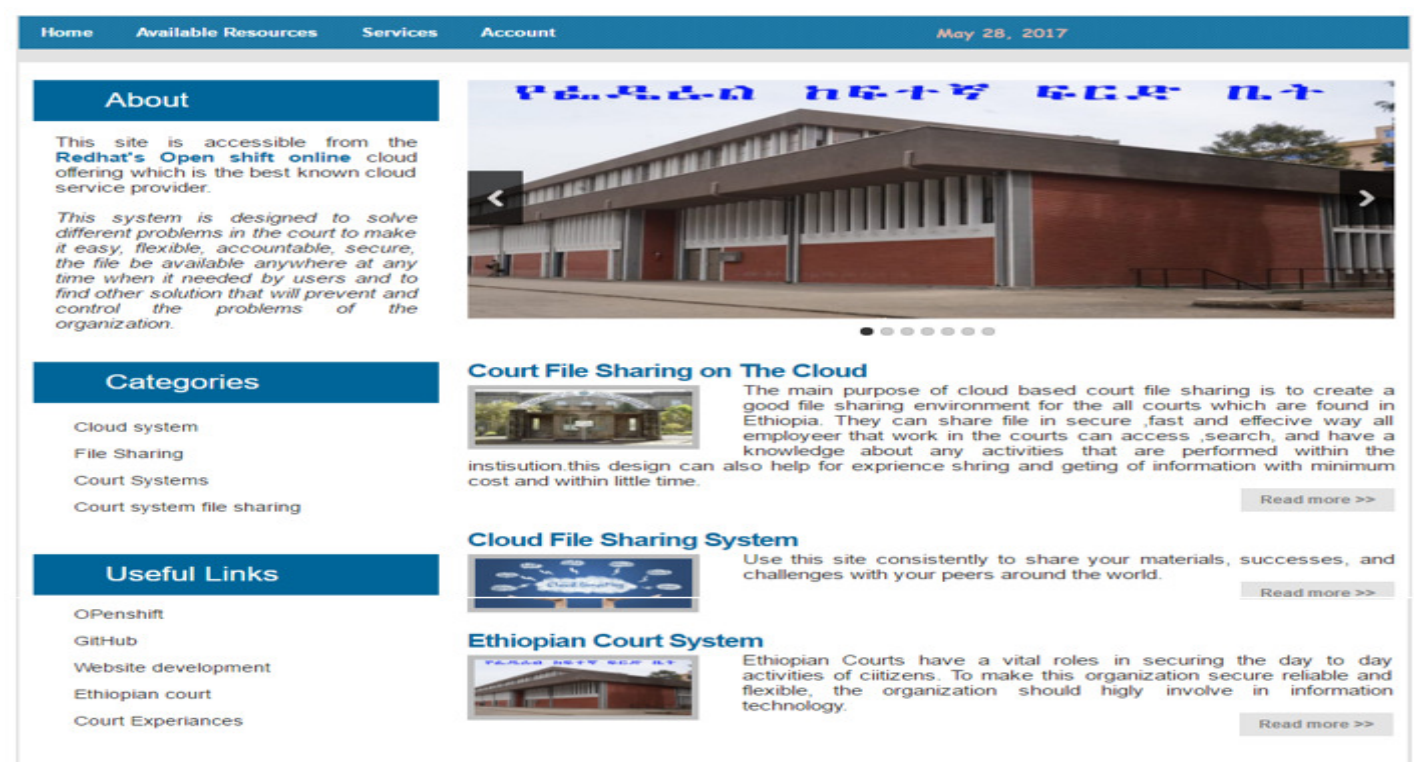

Figure::Home Page of CBCFS 


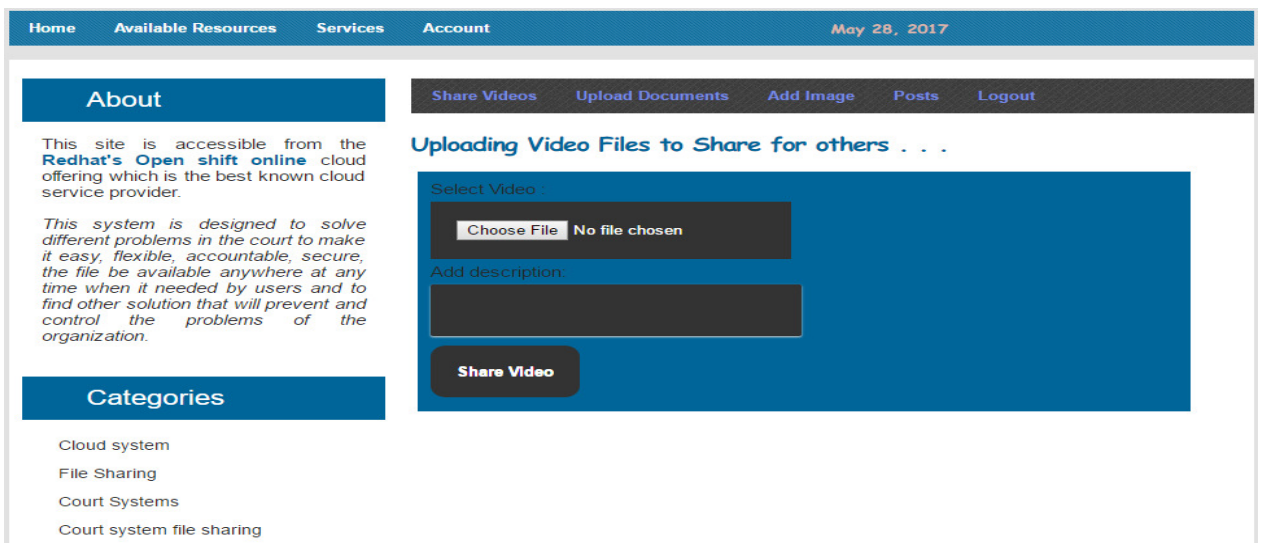

Figure::File upload page of CBFS

\section{Finding and Discussion}

The Current trained of court file sharing in Ethiopia is through manual method where the documents, files are used by the whole employees in manual way and also those documents and best files are not published or electronically available for other organizations and other users. The manual methods of this file sharing through the whole country need high cost and more time. Furthermore, the court officers did not access the file as they need and could not collaborate to share those files with their peers. The proposed cloud based platform architecture and the implemented prototype creates common way to share different type of court documents and files. This cloud base platform architecture is not only cost effective and interactive but also it is easy for collaboration, sharing and accessing the files and documents to have the same knowledge and same materials on their professions. In addition, the court officer can conduct online discussion by raising specific issues and forwards their challenges and solutions. When we Compared our CBPCFS system with the current manual method, it is resource full, interactive and supported by current technologies and tools but it does not mean it replaces the whole manual resource usage rather it is used as a bridge by supporting and increasing availability and collaboration with other shared file provider's, court officer and other worker. Therefore, the proposed cloud based platform architecture increases availability and resource sharing of the court resources, files and knowledge among the provider to other officers. This reduces cost of providing and distributing of court files that reduces losing of file, lack of having the same knowledge about the same case and lack of technologies. It increases ability of the officers by using the system as knowledge gaining network and self-learning environment.

The proposed architecture and the implemented prototype seems to have capability of sharing and accessing resources of all types such as documents (word document, PDF files, text files, excel files), pictures, audios, videos and other types of court information. Also the prototype is customizable and managed by the cloud provider which reduces management overhead, the interactive user interface allows to easily registering and login to the system to access all available files and to share their files and data to others, therefore increases interaction of all court officer. The tools selected to design the prototype is based on open source technologies, which allow future development with less effort, which can be affordable and manageable by the economy of the country. The prototype has been developed from the open source cloud tool (Open Shift online) selected after evaluating several available tools. In Open Shift online, the applications are typical web applications that will run on Open Shift. At this time, Open Shift is focused on hosting web applications. When a new application is created, a URL (http:// https://api.starter-us-west-2.openshift.com) with name of the application and the name of the domain is registered in DNS. A copy of the application code is checked out locally into a folder with the same name as the application. With each new application that is created with the client tools, a remote Git repository is populated with the selected cartridge, which is then cloned to the current directory on the local machine. There are four components that make up an Open Shift online application: domain (file sharing), application name (court file sharing), Alias and Gitrepository. Most of Open Shift online application life cycle has four processes: code, build, deploy and manage. The code involves the development of application code with the desired language and tools. The build process builds applications, Open Shift online supports various build mechanism for this purpose. The application deployment process involves making any required changes to the application code, committing those changes to the local repository, and then updating the remote repository, deploying to Open Shift online and managing.

\section{Conclusion}

In this study, we have presented the community cloud platform architecture and prototype implementation of court file sharing program named CBPCFS for sharing and accessing of files and document which are found in the court area. Hence, this study introduce the concept of Designing of cloud computing in the court sectors to share and 
access court file and documents to make the court officers more capable in their profession and technology adaption. CBPCFS were designed based on CCRA reference architecture and Kruchten $\mathrm{s} 4+1$ architectural view model as a baseline. This CBPCFS architecture focused on sharing and accessing of different files and document to increase availability with low cost and to create a good file sharing network the courts. It facilitates equal sharing of any files that help the user to have the same knowledge about the same thing where ever they are and also they can have a file whenever the user needed it. High level conceptual architecture and different views of the architecture are shown. Red hats Open Shift online cloud computing platform as a service technology was used to develop the prototype as well as to share and access files and documents of courts. So the CFS cloud portal prototype was developed to test usability of the architecture. Then the court officers and other users can easily share and access any files and document through the portal using their desktop computer and laptops to develop ability, skill and experience. Consequently, the CFS users are capable not only to handle or manage their file sharing of files but they can learn, adapt the technology and they can share experience.

\section{Acknowledgment}

My first thank is for my almighty GOD. The authors' greatest fear is forgetting someone, so I start off by saying thank you to all. If your name is not mentioned, please forgive me! Thanks go to Dr. Ravindra Babu at school of computing, at Adama Science and Technology University, who served as my advisor supervisor during the course of writing this dissertation. Thanks all my best friends for their help all the way in this thesis writing especially (Elifenesh Yitagesu ). I would be negligent if I did not mention my family, my parents who have supported me through the thick and thin of this MSc studies. Last but not least, all Software Engineering department members, lecturers and students for the different discussions, challenges and experiences shared during the this MSc. Course.

\section{Computing Interest}

The authors have not declared any conflict of interests.

\section{References}

1Kavita, 2. U. (April - June 2012). Cloud Computing Process Model in Supply Chain. IJMBS.

achalakul, p. r. (July 2009). the software prototype of civil court case managment in Thailand. International journal of software engineering and its applecation.

Amazon Web Services, I. o. (December 2015). Overview of Amazon Web Services. Amazon Web Service.

Ameena Mehar, M. S. (October 2014). A CLOUD SECURITY FRAMEWORK FOR DATA SHARING IN DYNAMIC groups. International Journal of Engineering \& Science Research, Vol-4(Issue-10).

Arijit Ukil, D. J. (September 2013). A SECURITY FRAMEWORK IN CLOUD COMPUTING INFRASTRUCTURE. International Journal of Network Security \& Its Applications (IJNSA).

Bart Jacob, M. B. (December 2005). Introduction to Grid computing. International Technical Support Organization. brief, I. i. (n.d.). cloud computing for the court. IJIS institute.

by Alexander Lomov, R. E. (2014). OpenShift and Cloud Foundry PaaS: High-level Overview of Features and Architectures. Altoros system.

Chang, V. (2010). A proposed framework for Cloud Computing adoption. International Journal of Web Services Research (IJWSR).

CHAPPELL, D. (2011). INTRODUCING THE WINDOWS AZURE platform. SPONSORED BY MICROSOFT CORPORATION.

Christian VECCHIOLAa, X. C. (2012). Aneka: A Software Platform for .NET-based Cloud Computing. Manjrasoft Pty Ltd, Melbourne, Australia.

Cohen, S. K. (2012). A Decision Framework for Cloud Computing. Hawaii International Conference on System Sciences.

Danan Thilakanathan, S. C. (2014). Secure Data Sharing in the Cloud. Department of Electrical Engineering, The University of Sydney.

Defining a framework for. (n.d.). In Cloud Computing. IBM Global Technology Services.

LLP, F. \&. (2013). A Practical Framework for Managing Cloud Computing Risk. In Cloud Computing. the Information Technology \& Outsourcing Practice.

Mathew, J. V. (jan 2014). Overview of Amazon Web Services. Amazon web service.

MATHEW, P. A. ( April 2012). SECURITY AND PRIVACY ISSUES OF CLOUD COMPUTING SOLUTIONS AND SECURE FRAMEWORK; International Journal of Multidisciplinary Research.

Neha Rawat*, R. S. (August 2014). Data Security Issues in Cloud Computing. OPEN JOURNAL OF MOBILE COMPUTING AND CLOUD COMPUTING, Volume 1.

Paper, A. O. (April 2012). Oracle Consulting Cloud Services Framework. Oracle.

R1, K. P. (2013). Applications of Green Cloud Computing in Energy Efficiency and Environmental Sustainability. IOSR Journal of Computer Engineering. 
rako, D. R. (21. may 2014). Research Designs. VIA University College.

Ranjan Kumar\#1, G. (feb,2014). Cloud Computing Simulation Using CloudSim. International Journal of Engineering Trends and Technology (IJETT).

Red-Hat. (2012). OpenShift platform features. In OpenShift platform features. Red Hat.

Sreedharan, S. (Mar. - Apr. 2013). Security and Privacy Issues of Cloud Computing; Solutions and Secure Framework. In Security and Privacy Issues of Cloud Computing (pp. 33-37). IOSR Journal of Computer Engineering (IOSR-JCE).

Stephen Kaisler, W. H. (2012). A Decision Framework for Cloud Computing. 45th Hawaii International Conference on System Sciences.

Systems, H. D. (May 2012). How to Improve Healthcare with Cloud Computing. In How to Improve Healthcare with Cloud Computing. Hitachi.

Team, R. H. (2014). OpenShift Online 1 User Guide. Red Hat.

UNDERSTANDING The Cloud Computing Stack SaaS, Paas, IaaS. (2011). In cloud U.

V.E.Unnamalai, J. (2014). Service-Oriented Architecture for Cloud Computing. International Journal of Computer Science and Information Technologies, no 5.

Varia, j. (January 2011). Architecting for the cloud:best practice. Amazon Web Services.

W. S. W. M. S. a. A. Haider. (2012). Electronic Court Records Management:. Journal of e-Government Studies and Best Practices.

Wan Satirah Wan Mohd Saman, A. H. (2013). E-Court: Information and Communication Technologies. Technology Management for Emerging Technologies.

Wondirad, A. ( 2014). AN OVERVIEW OF THE ETHIOPIAN. United Nations Development Programme.

Wyk, D. B. (may 2013). Research design and methods. university of the western cap.

Zeyana Saif Alkindi, J. H. (September 2015). A Conceptual Architectural Framework of Cloud Computing for Higher Educational Institutions in the Sultanate of Oman. Journal of Emerging Trends in Computing and Information Sciences, Vol. 6. 